\title{
Homem com homem, mulher com mulher: paródias sertanejas no interior de Goiás*
}

\author{
Silvana de Souza Nascimento**
}

\section{Resumo}

Este artigo apresenta uma reflexão etnográfica a respeito da relação entre gênero e sociabilidade no sudoeste de Goiás, em pequenos municípios rurais. A proposta é ampliar o olhar sobre as relações de gênero no meio rural e descrever e compreender um processo social - um universo de festividades - que privilegia sociabilidades entre pessoas do mesmo sexo. O texto pretende mostrar que, para além da divisão sexual do trabalho e da complementaridade entre os sexos, as relações do tipo "mesmo sexo" põem em xeque a ideia de antagonismo entre homens $e$ mulheres dentro da matriz da heterossexualidade e, além disso, problematizam a reprodução mecânica da família patriarcal nas relações de gênero no campo.

Palavras-chave: Gênero, Sociabilidade, Mundo Rural.

\footnotetext{
* Recebido para publicação em 22 de março de 2010, aceito em 19 de março de 2011.

** Professora Adjunta II de Antropologia da Universidade Federal da Paraíba, departamento de Ciências Sociais do campus Litoral Norte. Coordenadora do Grupo de Pesquisa "Etnografias Urbanas - Diferenças e Alteridades", da UFPB/Cnpq e pesquisadora associada do NAU - Núcleo de Antropologia Urbana da Universidade de São Paulo.simples.humano@gmail.com
}

cadernos pagu (39), julho-dezembro de 2012:367-402. 
Homem com homem, mulher com mulher

Men with Men, Women with Women: Country Parodies in Goiás

\begin{abstract}
This article will present a brief ethnographic study of the relationship between gender and sociability in the southwest of Goiás, in small rural villages. The proposal is to expand the view on gender relations in rural areas and provide a social process - a universe of festivities - which emphasizes sociability between the same sex without subtracting the hegemony of heterosexual relationships and sexual division of labor. This article aims to show that same-sex relationships are challenging the idea of antagonism between men and women within the matrix of heterosexuality and, moreover, critique the mechanical reproduction of the patriarchal family in gender relations in the rural world.
\end{abstract}

Key Words: Gender, Sociability, Rural World. 


\section{Prelúdio}

Pra fazer tudo que eu gosto não tem lugar e nem horário moro embaixo do chapéu não carrego calendário, minha linguagem é simples não conheço dicionário, no rodeio sou doutor, mas na escola só fiz o primário (Verso de festas de peão, narrados durante os rodeios).

A imagem rústica do peão ou do vaqueiro, que se mistura à paisagem árida, faz parte do imaginário do sertão brasileiro. A descrição de sua "rudeza" confunde-se àquela dos animais. Ao descrever um estouro de boiada, Euclides da Cunha, em Os Sertões, desenha uma cena típica em que vaqueiro e boi confundem-se:

destroem-se em minutos, feito montes de leivas, antigas roças penosamente cultivadas; extinguem-se, em lameiros revolvidos, as ipueiras rasas; abatem-se, apisoados, os pousos; ou esvaziam-se, deixando os habitantes espavoridos, fugindo para os lados, evitando o rumo retilíneo em que se desempenha a "arribada". (...) E sobre este tumulto, arrodeando-o, ou arremessando-se impetuosos na esteira de destroços, que deixa após si aquela avalanche viva, largado numa disparada estupenda sobre barrancas, e valos, rédeas soltas, soltos os estribos, estirado sobre o lombilho, preso às crinas do cavalo - o vaqueiro! (Cunha, 1995:190).

Nesta passagem, ambos se misturam num mesmo personagem. Cunha descreve o vaqueiro como uma "rochaanimal-homem" que, apesar da aparência fraca e fatigada, é "antes de tudo um forte". Bernardo Élis, escritor goiano, também fala da relação ontológica do homem com o boi no conto "Joãoboi" (1994). Essa imagem do homem sertanejo, "bichohomem", também está presente na obra de João Guimarães Rosa, 
como em "Conversa de Bois", em Sagarana (1984) e também no conto "O Boi de Guia", de Cora Coralina (1985).

As representações literárias sobre o homem sertanejo tocam em certas questões observadas no sudoeste de Goiás, em pequenos municípios rurais, onde realizei pesquisas de campo de 1996 a 2005, durante o mestrado e o doutorado em Antropologia pela Universidade de São Paulo. Nessa região, há uma relação quase visceral dos homens com seus bois, que acompanha os períodos de festa e de trabalho. Nas festas, a relação simbiótica homem-animal apresenta uma imagem hiperbólica, que mistura rusticidade e sexualidade.

Durante as romarias, homens adultos assumem os papéis de carreiros e guiam carros de bois até o santuário de Trindade para a Festa do Divino Pai Eterno, nas proximidades da capital Goiânia. Durante a romaria, ser carreiro - "homem de pau comprido", como diria Guimarães Rosa - é um status que torna uma atividade masculina rotineira nas zonas rurais (a pecuária) visível e reconhecida socialmente.

Por sua vez, nos rodeios, jovens rapazes, de diferentes classes sociais, desde filhos de grandes fazendeiros até peões $e$ trabalhadores rurais, tornam-se uma das mais desejadas atrações em cima de seus cavalos. Vestem-se de coloridas roupas de couro, ao estilo country, franjas se balançam nas laterais das calças justas, houve-se o retinir das esporas das botas, com leves saltos e bicos finos, cintos grossos com grandes presilhas prateadas ou douradas afinam as cinturas, o chapéu encobre parte do rosto altivo. Mulheres e moças esbanjam os mais variados decotes, exibem costas, peitos, pernas e braços de fora. As calças compridas e justas destacam coxas e ancas. Seja nas romarias, seja nos rodeios, os momentos festivos evidenciam uma maneira articulada de exposição dos corpos que, por meio das vestimentas e gestos, dá forma a eles de maneira bastante exuberante. 
Assim, partindo de uma cultura camponesa rústica ${ }^{1}$, em que as pessoas sertanejas são representadas pela resignação $e$ discrição, pela aridez do corpo e do ambiente "semi-selvagem", para manifestações festivas rurais que misturam rudeza $e$ espetáculo, religiosidade com lazer e sexualidade, este artigo pretende problematizar a relação entre gênero e sociabilidade em pequenos municípios rurais por meio de uma leitura etnográfica sobre diferentes festividades, especialmente católicas, no sudoeste de Goiás. Tratarei da Romaria e Festa do Divino Pai Eterno, da Festa de Santos Reis e das Exposições Agropecuárias para mostrar dinâmicas que se entrelaçam entre essas comemorações e que criam formas de sociabilidade $e^{2}$ que replicam e superpõem pessoas, corpos e relações sociais que assumem a forma "mesmo sexo" $e$ exageram atributos de feminilidades e de masculinidades.

Nesse circuito de festas, que compreende a cidade de Trindade, próximo à Goiânia, e municípios rurais como Mossâmedes, Sanclerlândia, Goiás, Itaberaí entre outros pequenos povoados, forma-se uma ampla rede que privilegia sociabilidades entre pessoas do mesmo sexo e por meio dela ensina-se que, desde a infância, homens e mulheres dificilmente se misturam

${ }^{1}$ Nas palavras de Antonio Candido (1987:21), "o termo rústico é empregado não como equivalente de rural ou de rude, tosco, embora os englobe. Rural exprime sobretudo localização, enquanto ele pretende exprimir um tipo social e cultural, indicando o que é, no Brasil, o universo das culturas tradicionais do homem do campo" (grifos do autor).

2 A ideia de sociabilidade, aqui, está vinculada a de encontro coletivo e não é usada no seu sentido estrito tal qual a definição de Simmel (1983). Para o autor, a sociabilidade é um processo lúdico de sociação que possui um valor em si, no qual a unidade se dá pela forma, pelo sentimento entre seus membros de estarem sociados. Segundo Simmel, a sociabilidade é definida como a pura interação entre os indivíduos, por meio de regras de tato e etiqueta, na qual as qualidades pessoais não são evidenciadas. Neste texto, as redes de sociabilidade definem-se como relacionamentos densos, que têm a forma "mesmo sexo", baseados em trabalhos de ajuda mútua e em laços de afetividade e amizade que separam homens e mulheres em redes de relações diferentes em determinadas ocasiões. 
publicamente nos encontros coletivos. Contudo, a lógica local que reza "homem com homem, mulher com mulher" não sedimenta um único modelo de heterossexualidade e de segregação sexual, recria diferentes feminilidades e masculinidades nas quais podem transbordar práticas, olhares e desejos não-ditos (Ferreira, 2008).

\section{O segredo revelado das mãos}

As diferenças a respeito da construção de feminilidades $e$ masculinidades colocaram-se logo nos primeiros dias de trabalho de campo no interior de Goiás, nos quais o meu próprio corpo foi classificado e compreendido como alguém que não fazia parte daquela convenção cultural, mas que era feminino.

A primeira noite em que passei na fazenda Paraíso, no município de Mossâmedes, em 1997, era véspera da partida para a romaria do Divino Pai Eterno. Eu iniciava os meus primeiros contatos com os moradores daquela localidade. Seu Tota, o dono da casa e uma das lideranças locais, propôs, então, um teste para mim, a moça que recém-chegava de São Paulo e conhecia muito pouco do mundo rural. Ele me pediu para descascar um "limão de fazer doce" e ficou ao meu lado, observando-me. Tentou fazer o mesmo, com seu canivete, mas logo desistiu. "Não é serviço pra homem", explicou. Mas ele pareceu ter ficado satisfeito com meu esforço e disse-me gentilmente que eu era "trabalhadeira", característica que terminei por incorporar, ou que me foi incorporada, ao papel de antropóloga. ${ }^{3}$ Então, tive a oportunidade de acompanhar e participar das atividades das mulheres durante alguns anos. A cozinha, um dos principais espaços femininos, passou a ser meu lugar de trabalho em duplo sentido, como mulher e antropóloga.

3 Esse episódio ilustra um dos elementos que me chamou a atenção durante os primeiros anos da pesquisa de campo: a importância do trabalho não apenas como uma atividade produtiva, mas como um valor que permeia o cotidiano $e$ as festas. 
Porém, minha posição mais participativa ao lado das mulheres também dificultou a minha aproximação juntos aos homens, pois os casados raramente se dirigiam publicamente às mulheres solteiras ou estranhas, como eu. Essa barreira em relação ao universo masculino mostrou-se, em certo sentido, reveladora: indicava a predominância de uma regra social que separava homens $e$ mulheres em espaços $e$ formas de sociabilidade diferentes, principalmente em lugares coletivos compartilhados por todos.

E para além da diferença de gênero, outras distinções se faziam presentes em primeira instância pela minha própria constituição corporal. Nessa localidade, geralmente, as pessoas se cumprimentam apenas com um leve aperto de mãos, sem praticamente apertá-las. Mesmo entre amigos íntimos quase não há cumprimentos com beijos no rosto, somente um meio-abraço, ou seja, colocando-se um braço no ombro do outro. Certa vez em que me apresentei para algumas pessoas, eu simplesmente estendi minha mão para fazer educadamente o cumprimento, disse meu nome sem contar minha proveniência, profissão, etc. No entanto, o contato por meio das mãos já informou que eu não era dali minhas mãos lisas, sem calos, hidratadas, finas. A diferença corporificada em relação às mãos das outras mulheres, calejadas pelo esforço do trabalho rural, era evidente. Porém, mesmo com as diferenças de classe, regionais e corpóreas, atribuíram-me um papel feminino e, por meio da observação participante, pude perceber a importância da segregação sexual - menos como uma forma de dominação masculina do que como um modo pelo qual as relações sociais são construídas e dão sentido às diferenças sexuais.

\section{A dominação conceitual da "família patriarcal"}

Aqui, será necessário abrir um parêntese e tecer alguns comentários sobre as teorias brasileiras a respeito do campesinato e sobre mulheres no campo. Paulo Rogers Ferreira (2008), em sua 
pesquisa sobre masculinidades e sexualidades de "afectos malditos" em Goiabeiras, no interior do Ceará, constrói uma argumentação crítica sobre o que ele chama de Texto Brasileiro (TB) sobre o campesinato e demonstra, em linhas gerais, que a ideia de "ordem moral camponesa" presente em autores consagrados como Candido (1987), Queiroz (1973), Moura (1986), Woortman (1990), entre outros, termina por fixar e enclausurar as sociedades camponesas num corpo mutilado, associado à religiosidade e à natureza, num modelo centrado na parentela, na heterossexualidade e na divisão sexual do trabalho. De fato, há um esforço dessa literatura em construir um modelo de campesinato baseado no trinômio trabalho-família-terra, ou Homem-Deus-Natureza, como quer Ferreira, e que se reflete em grande parte da produção sobre mulheres rurais no campo. Nessa produção, "rural" muitas vezes torna-se sinônimo de "patriarcal".

Ao realizar um pequeno mapeamento sobre a produção nas ciências sociais que se refere a relações de gênero, mulheres $e$ meio rural no Brasil, podemos observar alguns problemas demarcados pelos períodos 1960-1980, 1980-2000 e 2000-2011.

O primeiro conjunto de textos (Silva, 1968; Fukui, 1975, 1976; Martinez-Alier, 1975; Paulilo, 1980; Saffioti e Ferrante, 1980; Muraro, 1983) apresenta perspectivas alinhadas às teorias marxistas $e$ procura denunciar as precárias condições de trabalho das mulheres rurais especialmente pelo avanço do capitalismo no campo. De acordo com esses estudos, antes da introdução da lógica capitalista no meio rural, as mulheres podiam viver em condições de igualdade de deveres e direitos em relação aos homens e ambos contribuíam para a produção familiar. No entanto, com as transformações geradas pela imposição do novo sistema econômico, as mulheres tornaram-se duplamente subordinadas, aos cônjuges e aos patrões.

O segundo conjunto de textos (Moraes Silva, 1992; Fischer e Albuquerque, 1995; Paulilo, De Grandi e Silva, 2000; De Grandi, 2000; Paulilo, 2000; Abromovay e Silva, 2000; Gouveia, 2003, Rodrigues, 1991; Grossi, 1995; Bittencourt, 1993; Mattos, 2001) segue diferentes 
linhas interpretativas, mas procura apresentar soluções para a subordinação e exploração femininas. As autoras desse período mostram que, por meio de movimentos organizados, as mulheres começaram a denunciar sua condição subalterna especialmente nos espaços públicos, a reivindicar igualdade de direitos e a valorizar o seu trabalho em seus aspectos sociais, econômicos e jurídicos.

Com mais ou menos nuances, grande parte dos estudos mencionados acima corroboram com a ideia de associar o modelo da família patriarcal às relações de gênero e à condição feminina no meio rural. Quando se fala, direta ou indiretamente, dos estudos de gênero no Brasil rural prevalece uma dominação conceitual de "família patriarcal". A preocupação crescente em pesquisar movimentos de mulheres evidencia essa dominação conceitual, como se o patriarcado se prolongasse dentro do sistema capitalista até hoje, e o propósito de mostrar focos de resistência feminina dentro de um modelo de dominação masculina de longa duração.

O terceiro conjunto de textos mais contemporâneos (Van Der Schaaf, 2003; Alves, 2003; Deere, 2004; Salvaro, 2004; Boni, 2004; Stropalosas, 2004; Portella e Ferreira, 2004; Cordeiro e Scott, 2006; Brumer, 2007; Sales, 2007; Paula Andrade, 2007; Buto, A., Silva e Hora, K., 2008; Melo e Duarte, 2010; Lisboa, 2010; Garcia et alii, 2011; Pires, Santos e Silva, 2011) já demonstra um crescimento de pesquisas sobre mulheres e relações de gênero no meio rural no Brasil e uma diversidade de olhares sobre a temática, embora falese pouco de direitos sexuais e reprodutivos e de sexualidade. Observam-se interesses especialmente em agricultoras do Sul do Brasil, o que resultou em uma coletânea da Revista Estudos Feministas (vol. 12, n ${ }^{\circ} 1,2004$ ), em mulheres do campo no Norte e Nordeste (Cordeiro e Scott, 2006) e da participação feminina na luta pela Reforma Agrária e sua inserção nos programas sociais (microcrédito, economia solidária, etc.). Há uma ênfase, de um lado, no trabalho feminino e na sua importância dentro do universo familiar e, de outro, na força política dos movimentos de mulheres 
rurais, que conquistaram um protagonismo na sociedade civil e na elaboração de políticas públicas para trabalhadoras rurais.

Vale destacar a crítica à noção de agricultura familiar (Paulilo, De Grandi e Silva, 2000; Abromovay, M., 2000; Gouveia, 2003; Garcia et alii, 2011) muito utilizada nos projetos das políticas públicas para a reforma agrária, ideia que tende a escamotear os conflitos e as diferenciações internas à unidade familiar e favorecer a dominação masculina. Por exemplo, a pesquisa coordenada por Loreley Garcia (2011) nos cariris paraibanos demonstra que a atuação de programas governamentais de desenvolvimento sustentável e de agricultura familiar, ainda que se proponha a trabalhar com a equidade de gênero, termina por reproduzir desigualdades entre os sexos. Contraditoriamente, ao mesmo tempo em que os movimentos de mulheres buscam equidade para ambos os sexos, eles são influenciados por políticas públicas que acreditam no ideal de uma agricultura familiar sustentável, na qual há uma complementaridade e harmonia entre homens e mulheres.

Ainda é importante ressaltar que as duas últimas revisões bibliográficas sobre estudos de gênero realizadas no Brasil primeiro, por Maria Luiza Heilborn e Bila Sorj (1999) a respeito de textos produzidos entre as décadas de 1970 a 1990, e depois por Miriam Grossi (2010), que contempla o período da década de 1980 até os anos 2000 - fazem poucas referências às produções sociológicas e antropológicas sobre sociedades camponesas, que muitas vezes aparecem subsumidas a outras temáticas. Talvez, a não referência aos estudos sobre meio rural mostra que o debate contemporâneo sobre gênero e sexualidade suponha que, no campo, permaneça uma organização "tradicional" de família que segue o velho modelo patriarcal e heterossexual. Como constata Mariza Corrêa (1994), a persistência do uso da noção de família patriarcal "achata todas as possibilidades imaginadas e tentadas, reduzindo-as a extensões de um núcleo homogêneo que não teria feito mais do que se expandir e progredir através do tempo e do 
espaço, vindo afinal ocupar o lugar que desde sempre lhe esteve reservado" (id.ib.:17). ${ }^{4}$

\section{Homem custoso e mulher trabalhadeira}

Voltando à Goiás e fechando o parêntese, no período de realização da pesquisa de campo, 1996 a 2005, pude acompanhar a Romaria do Divino Pai Eterno que se dirige para o santuário de Trindade, a poucos quilômetros da capital Goiânia, e outras festividades que, de certo modo, dialogam com essa romaria $e$ apresentam elementos que se recriam e se replicam como a organização da festa, a segregação sexual, a relação homensanimais, a religiosidade, a elaboração da comida e a celebração da cozinha, entre outros.

Atualmente, a Festa do Divino Pai Eterno atrai, no início de julho, mais de dois milhões de devotos provenientes de várias partes do Centro-Oeste e do Brasil, dos quais cerca de mil chegam à cidade em carros de bois. ${ }^{5}$ Durante o trabalho de campo, de 1997 a 2005, o número de fiéis que se dirigiam ao santuário de Trindade chegava a 500 mil pessoas, das quais aproximadamente 10 mil chegavam à festa em carros de bois. Nos últimos anos, o

4 Lia Machado (2000) também faz a mesma crítica ao conceito de patriarcado: "mesmo quando repensado e redefinido para dar conta de sua forma contemporânea, parece-me preso às referências clássicas do domus latino e do oikos grego, fixando fortemente o que há de semelhante em histórias tão distintas, e construindo um mito dos tempos imemoriais da dominação familiar e sexual que atravessaria toda a antiguidade, a idade média e a moderna, chegando à contemporaneidade" (id.ib.:6). Desse modo, outras formas de organização familiar ficam subsumidas ao domínio patriarcal, no sentido teórico e histórico.

5 A Festa do Divino Pai Eterno homenageia uma imagem que, segundo a história de fundação do santuário, foi encontrada por um casal de lavradores no século 19: um medalhão que contém quatro figuras sagradas, o Pai, o Filho e a Virgem Maria entre eles sendo coroada pela pomba branca do Espírito Santo. O santuário é dirigido pelos padres redentoristas, que também estão na direção de centros religiosos como o de Aparecida, em São Paulo, e Bom Jesus da Lapa, na Bahia. Para mais informações sobre a festa acessar www.divinopaieterno.com.br. 
número de carreiros - geralmente pequenos produtores de pecuária leiteira e trabalhadores rurais agregados - diminuiu consideravelmente. Essa redução deve-se a múltiplos fatores. Houve, nos últimos quinze anos, uma transformação na economia rural local, que tem se apropriado de novas tecnologias produtivas para atender ao mercado regional, o que significa que o tempo em que era realizada a colheita (no mês de junho) entre pequenos proprietários hoje tem se modificado devido à presença de grandes latifúndios. Além disso, a organização religiosa da celebração, sob domínio da ordem redentorista, tem transformado a Festa do Divino Pai Eterno, que antes era apropriada por diferentes manifestações do catolicismo rústico ou popular ${ }^{6}$, em um ritual ligado à Renovação Carismática da Igreja Católica.

Outro fenômeno, que parece ter menos visibilidade, mas a mesma importância, foi a entrada na universidade de moradoras dos pequenos municípios rurais, no início dos anos 2000, o que tem modificado o cotidiano do trabalho familiar e criado tensões nas famílias nucleares. Essas mulheres, especialmente professoras, tinham uma centralidade na organização das festas e eram responsáveis pela alimentação, recepção das visitas e convidados, pelas novenas e rezas e pela circulação das informações ao longo das festividades. Sua ida para as universidades transformou ou tem transformado não só a dinâmica das festas como das famílias, já que o tempo que era dividido entre o trabalho no cotidiano e o trabalho na festa, agora tem que ser repartido com o tempo dos estudos. E entrou em tensão com a falta de interesse dos homens em terminar os estudos, mas aprimorar-se nas técnicas de produção leiteira com outros homens e não por meio de uma formação científica especializada. Foi nesse momento de transição que interrompi minhas pesquisas de campo para finalizar a tese de

\footnotetext{
${ }^{6}$ Maria Isaura P. de Queiroz (1973) define o catolicismo rústico como formas de religiosidade populares católicas baseadas em festas coletivas, danças, rezas, romarias que se realizam, tradicionalmente, sem a interferência direta de padres ou representantes oficiais da Igreja. Esse catolicismo está baseado no culto aos santos, realizado especialmente durante as festas de padroeiro.
} 
doutorado. Assim, este texto é uma espécie de retrato etnográfico registrado até 2005 e que certamente sofreu transformações.

A Romaria do Divino Pai Eterno se inicia com os preparativos nas zonas rurais e pude acompanhar, durante quatro anos, as famílias romeiras do município de Mossâmedes, com aproximadamente 5 mil habitantes, a 150 quilômetros de Goiânia. Os preparativos são divididos entre homens e mulheres. Estas permanecem muitas horas na cozinha e esse é um momento em que mães, filhas, noras e cunhadas trabalham de forma coletiva. Também aproveitam a ocasião para contar casos, piadas e principalmente fofocas.

Para fora da cozinha, os homens dedicam-se à montagem dos carros de bois que vão conduzi-los até o santuário. No cotidiano, ainda se observa o uso desse meio de transporte para carga e para arar as terras ${ }^{7}$, principalmente em pequenas propriedades. Cabe aos homens cuidar das atividades ligadas ao gado e dos trabalhos agrícolas (produção de feijão, arroz, milho, cana-de-açúcar e mandioca) voltados para a subsistência, que se encontram hoje em processo gradativo de diminuição.

Nos dias que prenunciam as festividades, os trabalhos não são suspensos. Segundo Klaas Woortmann (1990), há três categorias comuns às populações camponesas, relacionais $e$ interdependentes, que constituem a sua ordem moral: a terra, a família e o trabalho, vinculadas aos princípios de honra $e$ hierarquia. Contudo, uma outra categoria mostra-se fundamental: a festa. Ela se mostra como um dos componentes centrais do universo de valores camponeses e sintetiza, rearranja e intensifica as relações de gênero, da família e da vizinhança. Na festa, essa ordem camponesa é celebrada e, ao mesmo tempo, excedida e pulverizada. Paralelamente à moralidade rural cristã, jovens moças

\footnotetext{
7 Diferentemente do vaqueiro, que viaja pelo sertão conduzindo manadas "selvagens", o carreiro conduz animais domesticados e treinados para esse tipo de função. Alguns animais são transmitidos de pai para filho, que acompanham seu crescimento, sua produção de leite, a gestação das vacas, os nascimentos dos bezerros, etc.
} 
paqueram homens casados, seminaristas buscam paixões (que algumas vezes levam a casamentos e ao abandono do projeto do celibato religioso), pessoas estranhas são acolhidas e desejadas. Uma profusão de volúpias faz com que estar junto a seus familiares, rever parentes e compadres, conhecer estranhos tornem a romaria mais que uma "caminhada para a terra santa".

Inspirada na pesquisa-experimento de Paulo Rogers Ferreira $(2008)^{8}$, e relembrando minhas experiências de campo, apesar de não ter observado de forma mais atenta relações "mal-ditas" (e talvez por ter, de certo modo, romantizado o universo rural), cenas de ciúmes, olhares apreensivos, gestos insinuantes, silêncios, ausências, corpos em exposição, etc. também me levaram a suspeitar da hegemonia de uma certa moral camponesa e de uma manipulação do discurso moralizante em determinadas ocasiões. Há momentos em que o discurso da moral camponesa impera reforçando a importância da relação terra-família-trabalho; em outros, como nos momentos festivos e encontros coletivos homossociais, essa moral é pulverizada e sublimada.

Durante a romaria, as famílias viajam por seis dias em carros de bois e acampam em fazendas. Os pousos são momentos de reunião familiar. Cada família extensa ${ }^{9}$ dorme e come debaixo do mesmo teto. Essa é uma situação peculiar em relação ao cotidiano, em que cada família nuclear possui a sua própria casa $e$, algumas vezes, a sua propriedade. A romaria possibilita uma ampliação da convivência entre parentes, intensificando as

8 Paulo Rogers Ferreira (2008) elabora uma etnografia a respeito de sexualidades em um povoado rural no sertão do Ceará e mostra a existência de práticas homossexuais e diferentes erotismos entre homens que são pais de famílias, práticas estas que não necessariamente põem em cheque sua virilidade e seu contrato sexual com mulheres por meio do casamento. $\mathrm{O}$ autor propõe uma nova leitura sobre as sociedades camponesas onde as infinitas possibilidades do corpo constroem uma ética e uma estética dos afectos.

9 O termo "família extensa" refere-se aqui a um conjunto de famílias nucleares, formado pelos filhos que casaram e saíram da casa dos pais para criar uma nova família nuclear em outra pequena propriedade. 
relações familiares. Nos pousos, todos(as) reúnem-se para a reza, organizada geralmente por mulheres ${ }^{10}$, com ou sem a presença de padres, que, por sua vez, participam dessas romarias apenas como visitas. Durante o trabalho de campo, observei frequentemente a presença de padres, monges e seminaristas acompanhando a romaria, mas eles não eram vistos como protagonistas centrais desse ritual. Algumas vezes, ouvi rumores e conversas irônicas de que dormiam juntos, o que causava certo estranhamento, mas não atitudes discriminatórias mais assertivas quanto à suposta homossexualidade de agentes da Igreja Católica. Muitos deles, aliás, eram admirados pelo público feminino pela sua beleza e jovialidade.

$\mathrm{Na}$ estrada, a cozinha é conduzida, por sua vez, pelos homens - o carro de bois carrega e protege todos aqueles bens que fazem parte do universo doméstico, como fogão, comidas, panelas, colchões, e as crianças. E a estrada abre passagem para as mulheres. Há duas maneiras femininas de fazer o percurso: dentro ou fora do carro. Na primeira, são as mães com crianças pequenas ou aquelas que preferem ficar com seus esposos ou as que simplesmente não gostam de andar. $\mathrm{Na}$ outra, estão as que optaram por andar na frente, e entre elas as que estão pagando promessas. Durante o percurso, formam-se alguns grupos: os das mulheres casadas e crianças que andam a pé, os das mulheres que vão dentro dos carros de bois, o das moças solteiras que caminham, de jovens rapazes a cavalo e o dos pagadores(as) de promessas, que fazem todo o percurso a pé. As mulheres que andam a pé seguem em grupos nos quais é quase nula a presença de homens com quem elas não têm vínculo de parentesco.

\footnotetext{
${ }^{10}$ As mulheres que coordenam as rezas são professoras que se formaram dentro dos princípios da Pastoral da Terra e da Teologia da Libertação. Ao contrário de uma suposta resignação feminina, as rezadeiras são livres, casadas, e apresentam projetos para o futuro voltados para o universo acadêmico e da política. Além disso, grande parte das mulheres dessa região (o que reflete, na verdade, uma situação comum em todo o Centro-Oeste) realizou laqueadura no início de seus vinte anos, recém-casadas, após o nascimento do segundo filho.
} 
Segundo o ethos local, mulheres casadas não devem circular nos mesmos espaços públicos que homens solteiros ou casados, contudo há relações jocosas observadas entre cunhados de sexos diferentes, especialmente se eles mantêm relações de compadrio.

De certo modo, durante a romaria, as mulheres têm a oportunidade de afastar-se temporariamente de seus maridos, sem, no entanto, que eles as percam de vista. Em contrapartida, elas estão sempre de olhos abertos em relação aos maridos, pois "homem é bicho custoso". As solteiras preferem distanciar-se das casadas, porque a viagem é um momento propício para paquerar e namorar os rapazes. Interessante observar que quando algumas moças resolvem acompanhar os carros, procuram ocupar um lugar de visibilidade, nas laterais dos carros, de modo que possam ser vistas e desejadas.

Mais facilmente que os homens, as mulheres podem ser taxadas de à toa já que, segundo o ditado local, "mulher, quando é custosa, não tem jeito”. A mulher à toa também está associada à imagem da mulher prostituta, cujos clientes são geralmente homens casados. No entanto, as mulheres que saem, de certo modo, da norma - desvio que pode ser muito tênue, como conversar com homens casados e permanecer num mesmo espaço que eles, até a prostituição - são classificadas como à toa e serão alvos constantes de fofocas, pois "o povo nunca esquece". A mulher à toa ou sem-vergonha pode ter comportamento que se assemelha ao masculino e desfrutar da possibilidade de ter amantes ou de ceder aos seus impulsos e agir como um bicho custoso. Nesse sentido, opõe-se à mulher trabalhadeira que deve, acima de tudo, alimentar sua família e, nas festas de romaria, acompanhar seu marido para "fazer o arroz quentinho" para ele.

De modo geral, para as mulheres, homem é bicho custoso, classificação que se atribui aos homens de forma naturalizada. Faz parte da construção da masculinidade hegemônica dar trabalho para as mulheres e, por outro lado, as mulheres corretas são as que trabalham e não ficam à toa. Segundo elas, é preciso estar atenta aos passos dos companheiros, pois eles estão mais 
sujeitos aos seus instintos animais e não podem ser totalmente domesticados. Se eles são especialistas na domesticação de animais, elas devem domesticá-los para que possam ter domínio sobre eles e isso tem um custo. Contudo, mesmo sendo custoso, eles também podem ser maridos bons, que não deixam faltar nada para a família e sustentam economicamente a casa. Essa associação local do homem ao bicho colabora para a desconstrução da associação que o senso comum faz da mulher em relação à "natureza" e dos homens à "cultura", tão problematizada na antropologia feminista no final da década de 1970 (Ortner, 1979), mas que ainda hoje permanece como um pano de fundo conceitual e político dos programas de agricultura familiar e políticas sociais voltadas para o campo.

O contraponto ao homem custoso, o "homem-de-paucomprido" descrito por Guimarães Rosa, é o homem mole, aquele que não cumpre devidamente seu papel masculino no modelo familiar hegemônico e, durante a festa, não é capaz de demonstrar a força necessária para resistir à viagem conduzindo os carros de bois. A categoria homem mole também pode ser acionada em situações nas quais as esposas estão descontentes com seus companheiros, quando estes não realizam, de forma complementar, a divisão do trabalho familiar. Mas essa categoria dificilmente é falada em lugares coletivos, apenas no espaço da intimidade da casa. Raramente ouviremos mulheres criticando seus maridos para estranhos ou em espaços públicos, mas esse silêncio não significa que elas não entrem em situações de conflito e negociações no espaço doméstico.

Tanto no cotidiano quanto durante as festas, ouvi algumas histórias a respeito de casos de adultério e desconfianças de mulheres em relação a seus maridos, sempre colocando a figura de uma mulher como aquela que os provocou. Um caso representativo, que foi contado entre mulheres, pode ser resumido da seguinte maneira: 
A mulher $\mathrm{X}$ roubou o marido de $\mathrm{Y}$;

a mulher $Y$, por sua vez, roubou o marido de Z;

a mulher $Z$ arrumou outro marido, que não era casado.

Essa "troca generalizada" - $\mathbf{X} \Rightarrow \mathbf{Y} \triangleq \mathbf{Z}$ - poderia prolongar-se indefinidamente. Os comentários sobre os casos de adultério apresentam uma mulher que roubou o marido de outra. Mesmo quando é o homem casado que comete o adultério, a mulher é o alvo do comentário, como "essa mulher é tão trabalhadeira... mas se ela fosse boa mesmo não ficava com esse marido". Os casos de adultério, muitas vezes, são conhecidos publicamente, mas tratados como segredo. Segredo revelado que não pode ser dito.

Paradoxalmente, mulheres casadas que só ficam nos carros também podem ser classificadas como "antiquadas" ou dependentes dos companheiros. Certa vez, uma das mulheres que nos primeiros dias andava a pé resolveu acompanhar o marido, ao lado do carro de bois, e foi alvo de comentários como ela não larga o marido. Largar o marido, mais para umas e menos para outras, mostra-se como um fato extraordinário que deve ser desfrutado.

$\mathrm{Na}$ chegada ao santuário, depois de uma semana de viagem, os carreiros tornam-se os protagonistas principais da festa durante o esperado "Desfile de Carros de Boi". O status de ser carreiro está ligado ao poder simbólico de uma certa masculinidade, legitimada pela religiosidade católica, que se impõe nos momentos de festa. Sua virilidade concretiza-se no trabalho que exerce como carreiro, demonstrando certa resistência, habilidade e experiência no trato com os bois, fazer o carro cantar, etc.

Além dos rituais religiosos, as comemorações no santuário oferecem vários tipos de lazer como bares e lanchonetes, parque de diversões, circo e rodeio. Uma das maiores atrações são as barraquinhas. A cidade torna-se um gigantesco camelódromo. Especialmente entre as mulheres, um dos assuntos centrais são as compras. Durante o dia, elas mulheres circulam ao lado de suas 
cunhadas, irmãs e comadres, não necessariamente em companhia dos seus maridos, que também fazem passeios pelo santuário junto com outros homens. No entanto, à noite, as casadas circulam pela festa ao lado de seus esposos, ou permanecem nas barracas, $e$ as solteiras, com autorização dos pais, passeiam em grupos ou com os namorados. Não se pode esquecer também que, entre um passeio e outro, elas são responsáveis pelo preparo de todas as refeições para a família e visitas de parentes.

Enquanto uma intensa movimentação acontece no centro de Trindade, no acampamento o grupo de Mossâmedes monta suas barracas num território comum e transforma-as em casas improvisadas. Nesse território, de um lado, reproduzem-se as mesmas atividades cotidianas, como o preparo das comidas, arrumar a casa, varrer o terreiro, etc.; de outro, e ao mesmo tempo, transformam-se essas atividades pela própria dinâmica da festa. A romaria transpóe para o mundo da festa uma parte fundamental do seu cotidiano: o universo da cozinha, lugar feminino $e$, ao mesmo tempo, da mais íntima convivência social entre parentes. Mesmo que, à primeira vista, esse universo demonstre a reprodução de um certo modelo de família tradicional rural, ou de uma ordem moral camponesa, coloca-se em evidência o universo doméstico e da cozinha - e não a dominação masculina - como uma das principais formas de sociabilidade.

Dessa maneira, a lógica homem com homem, mulher com mulher permite a construção de redes homossociais que não reproduzem a divisão sexual do trabalho de forma engessada, $e$ mostram que a segregação sexual não leva necessariamente ao binômio privado-feminino, público-masculino tampouco à dominação patriarcal. Observa-se um modo de relação que privilegia sociabilidades entre pessoas do mesmo sexo, como se houvesse um certo tipo de "homossociabilidade" que exclui um dos sexos nas situações envolvendo reuniões coletivas, mas reúne e condensa pessoas do mesmo sexo. Como afirma Nicole Claude Mathieu (1991:241), "a segregação estrita entre os sexos 
pode dar lugar a formas de solidariedade não-institucionalizadas entre as mulheres".

Essa forma de sociabilidade tem uma relação direta com a construção da pessoa. Mais do que se reconhecer como mulher ou homem por oposição ao sexo oposto, ou por oposição a um grupo homossexual (invertendo o raciocínio de Monique Wittig [2001] que se opõe a modelo da heterossexualidade e da ideia binária de "homem" e "mulher"), ser homem ou mulher significa estar reunido com outros homens ou com outras mulheres. Para essa autora, a identidade das "mulheres" se constrói na sua relação com seu oposto, os "homens", relação hierárquica que implicaria obrigações pessoais e econômicas, sendo a principal delas a da reprodução. A recusa em tornar-se heterossexual seria a negação de tornar-se "mulher" ou "homem.

O que faz uma mulher é uma relação particular com um homem, relação que nós chamamos anteriormente de servidão, relação que implica obrigações pessoais e físicas assim como obrigações econômicas, relação a qual as lésbicas escapam ao recusarem tornar-se ou permanecer heterossexuais (id.ib.:63, tradução minha).

Tendo como foco a experiência goiana, "as mulheres" são produtos e produtoras não somente de uma relação social com os homens, mas também de uma relação social entre elas. Se seguíssemos a teoria de Wittig, encontraríamos em Goiás um caso típico de contrato heterossexual - do que ela chama de pensamento straight - que imporia às mulheres uma obrigação absoluta da reprodução e, por consequência, da reprodução da sociedade heterossexual. No entanto, a recusa de uma opção pela heterossexualidade, como afirma Judith Butler (2003), "reproduz o tipo de binarismo disjuntivo que ela mesma caracteriza como o gesto filosófico divisório da mentalidade hetero". E ela completa:

a disjunção radical proposta por Wittig entre heterossexualidade e homossexualidade é simplesmente 
falsa, há estruturas de homossexualidade psíquica no âmbito das relações heterossexuais, e estruturas de heterossexualidade psíquica no âmbito da sexualidade $e$ dos relacionamentos lésbicos e gays (Butler, 2003:76).

Ainda que o modelo heterossexual seja normativo $e$ constituído por relações de poder, assim como todos os dispositivos de sexualidade ao longo da história (Foucault, 2001), ele não necessariamente descarta as relações do tipo mesmo sexo. "A heterossexualidade não é a única manifestação compulsória de poder a instrumentar a sexualidade" (Butler, 2003:76).

Retomando Wittig (2001), a sociedade heterossexual é fundada na necessidade do "outro-diferente" e na ideia da "diferença", sob a qual estão mascarados os conflitos $e$ as desigualdades. A autora afirma que essa sociedade normaliza a sexualidade dominante e faz da diferença dos sexos uma diferença naturalizada e não construída culturalmente. Tendo em vista a etnografia apresentada aqui, a heterossexualidade pode estar baseada, de um lado, na ideia do "outro-diferente" e, de outro, na ideia do "semelhante". É a partir da observação do real de que todas as mulheres têm algo em comum, seja um traço "biológicoanatômico" seja social, que elas se definem como mulheres. Isso vale também para os homens. No caso goiano, é a relação same sex que constrói homens e mulheres, que se reconhecem enquanto tais e conformam regras de sociabilidade. Por meio das relações do tipo "mesmo sexo", desde a infância se aprende que cada sexo dificilmente se mistura nos espaços coletivos.

Para não adentrar na nebulosa problemática das diferentes concepções a respeito da identidade de gênero, penso numa perspectiva mais afinada com a teoria de Marilyn Strathern (1988) sobre gênero, que para ela é um conceito que diz respeito a uma relação que pode ser do tipo cross sex (sexo cruzado) ou do tipo same sex (mesmo sexo). Para Strathern, "gênero" não se refere a um problema de identidade e sim a 
categorizações de pessoas, artefatos, eventos, sequências, etc. que se fundamentam em imagens sexuais - nas maneiras pelas quais a nitidez das características masculinas $e$ femininas torna concretas as ideias das pessoas sobre a natureza das relações sociais (2006:20).

A antropóloga faz uma crítica ao modelo ocidental de antagonismo sexual e de identidade de gênero. Neste modelo, a identidade individual aparece em primeiro plano, à qual a sociedade vincula papéis sexuais com fronteiras definidas e fixas. As categorias sociais tornam-se a moldura conforme aa qual homens e mulheres devem se comportar e confinam o gênero no âmbito da experiência individual. Para a autora, o modelo do antagonismo sexual obriga a uma definição antitética de cada sexo, e o que se perde nisso é a percepção do que a diferenciação de gênero pode tratar - oposições, justaposições, duplicações, exclusões.

As análises que lidam com gênero como identidade - com a experiência de homens $e$ mulheres em serem homens $e$ mulheres - tomam as relações entre os sexos como axiomáticas; este é o lugar no qual a masculinidade e a feminilidade se enfrentam (Strathern, 2006:110).

A partir de um modelo de sociabilidade rural, gênero pode ser pensado a partir de redes de sociabilidade que se associam por semelhanças entre pessoas do mesmo sexo, que não possuem fronteiras fixas dadas pelas unidades familiares nem pelas relações de parentesco. Contudo, é preciso reconhecer que esse modelo não está aberto, numa primeira instância, a modelos nãoheterossexuais e, mesmo com a existência de pessoas e relações que não se adequam à heterossexualidade normativa, terminam por reproduzi-la e podem ser vistos como "desvios institucionalizados" (Mathieu, 1991).

O exemplo dos berdaches ilumina um caso que observei durante a pesquisa de campo: uma "mulher", cabeleireira 
conhecida em uma cidade observada e uma das mais procuradas pelas noivas para arranjos de cabelo e maquiagem para $\mathrm{o}$ casamento, que vive com um homem, que é o manicuro no seu salão de beleza. Ela nasceu "homem", mas se veste, fala, comporta-se como uma discreta "mulher" casada da sua região, tipicamente goiana (cabelos longos, alisados com "escova", pintados de loiro, vestido delineando as formas arredondadas $e$ sandálias de saltos). Ela se vê como uma mulher e reivindica essa identidade principalmente quando seus amigos de infância a chamam pelo seu nome masculino de batismo. Além disso, ela tem sua clientela feminina assídua e não é alvo de xingamentos em público, como é o caso de outra pessoa que também se desvia, de certa forma, da norma, mas não se veste segundo os padrões femininos goianos e faz questão de se mostrar diferente do modelo (usa sempre roupas mais extravagantes, saias curtas de couro, maquiagens mais fortes, perucas, saltos plataforma). Esta pessoa é muito mais alvo de maus-tratos por parte da população e é taxada como sem-vergonha, qualidade pejorativa que também remete à imagem das mulheres prostitutas como descrito anteriormente. ${ }^{11}$

\footnotetext{
${ }^{11}$ Esses dois casos evocam a figura do pané entre os índios guayaki descritos por Pierre Clastres (1974). O pané é definido como um homem que é incapaz de ocupar a posição de caçador e que termina por perder a sua própria natureza e é obrigado a renunciar à sua masculinidade. $\mathrm{O}$ autor descreve dois exemplos. $\mathrm{O}$ primeiro é o do índio Chachubutawachuggi, que foi recusado pelas mulheres, pois não exercia as funções de caçador e não tinha um arco (seja por maldição de não ter habilidade para calçar seja por simples incompetência técnica). Ele era alvo de zombaria e desprezo até mesmo por parte das crianças, que o respeitavam menos que os demais adultos. Mesmo insistindo em querer ser homem, ele estava excluído do mundo masculino e do feminino. Assim, Chachubutawachuggi não tinha lugar social e era visto como anormal. O segundo personagem é Krembégi, que sabia tecer, tinha um cesto, vivia como uma mulher e tinha os cabelos mais longos. Segundo Clastres, ele era um homossexual que fazia parte do mundo das mulheres e não era desprezado pelo grupo.
} 


\section{Replicações: a celebração da cozinha}

Ao longo do ano, acontecem outras festividades que replicam certos elementos presentes na Festa do Divino Pai Eterno. Esta é uma das principais referências, materiais $e$ simbólicas, para a organização das demais festividades da região, como a do Divino Espírito Santo, na cidade de Mossâmedes, em agosto; a Festa de Santos Reis, no povoado de Mirandópolis, em janeiro; e a exposição agropecuária na cidade de Sanclerlândia, em julho.

Na Festa do Divino Espírito Santo, que acontece no último final de semana de agosto, na época da seca, há vinte anos, foi instituída uma romaria de carros de bois, uma reprodução em miniatura daquela para o santuário de Trindade. Essa romaria dura somente dois dias e há apenas um pouso, em que todos os carreiros se reúnem. Contudo, a participação maior é masculina. Aqui e também na de Santos Reis (em janeiro), observa-se a centralidade das folias, rituais tradicionais que envolvem grupos de homens, cantadores e tocadores. Os giros das folias se iniciam na preparação das festividades, quando os foliões circulam pela vizinhança para convidar a população e arrecadar fundos para as comemorações. Antigamente, os foliões giravam (circulavam) pelas fazendas a cavalo e viajavam dias convidando os moradores da zona rural para a festa na cidade. Atualmente, os percursos são mais curtos, mas sua estrutura permanece a mesma: eles passam de casa em casa, com a bandeira do Divino Espírito Santo ou dos Santos Reis, realizando rituais de reza e canto, intercalando paradas para almoço e pouso. ${ }^{12}$ Com a diminuição do tamanho

\footnotetext{
12 Tradicionalmente, o grupo de foliões era composto por um embaixador ou mestre - que comandava a folia e puxava os versos da cantoria; um gerente responsável pela organização e conduta do grupo; os cantores - divididos em diversas vozes, que podiam chegar até seis; e os instrumentistas - violões, violas, caixas, pandeiros e sanfona, mas que também podiam ser cantores. Atualmente, os grupos são dirigidos apenas pelo mestre, que exerce as antigas funções de embaixador e gerente. E repete-se a mesma cantoria de chegada, seguida da reza
} 
das folias, e a participação estar restrita a foliões mais idosos $e$ alguns adultos, já que os jovens raramente demonstram interesse por elas, continua-se dançando a tradicional catira. Ela é uma antiga dança, realizada apenas pelos homens, com movimentos corporais ritmados, palmas, batidas dos pés e canções, puxadas também por um mestre, com temas não religiosos referentes a mulheres, namoros, histórias de adultério etc. Tanto as folias quanto as catiras podem ser pensadas como espaços de solidariedade masculina, com rígidas regras de comportamento e etiqueta, que se constroem para fora do universo do trabalho e do espaço doméstico, que também incitam a competição (Vale de Almeida, 2000). Assim, prevalece o modelo de segregação sexual e da homossociabilidade no qual homens - foliões e carreiros - e mulheres - cozinheiras e rezadeiras - participam da festa de maneiras diferentes.

$\mathrm{Na}$ Festa de Santos Reis, que acontece no povoado de Mirandópolis (zona rural de Mossâmedes ${ }^{13}$ ), a disposição dos(as) participantes nos lugares onde se organizam as rezas apresenta uma recorrência que está visivelmente demarcada no espaço: mulheres na varanda e no interior da casa, homens no terreiro. Ambos circulam em todos os lugares, mas há uma grande concentração masculina no terreiro e feminina na varanda e na cozinha. Esse arranjo também pode ser notado em pequenas comemorações. Por exemplo, quando alguém faz aniversário e convida um grupo de foliões para dançar catira em sua casa. Essa dança é realizada na sala e é assistida pelas mulheres da porta, que desemboca na cozinha, ou seja, da porta que leva ao interior da casa. Na porta da sala que dá para a rua ficam outros homens, que não participam da dança. Certa vez, quando eu fui assistir a uma catira e estava assistindo à dança na porta que dá para a rua,

do terço diante do altar, depois uma parada para jogar truque (truco) ou dançar a catira, e finalmente a cantoria de despedida (Brandão, 1982).

${ }^{13}$ Esta festa atualmente recebe 4 a 5 mil pessoas e tem tomado proporções muito maiores do que as celebrações que acontecem na cidade de Mossâmedes. 
veio ao meu encontro uma mulher, uma das moradoras da casa, convidou-me para entrar pra dentro, ou seja, entrar na casa e ficar na cozinha, junto com as outras mulheres. No terreiro, tanto depois da catira quanto depois da reza durante as novenas de Folia de Reis, o mestre distribui cachaça somente para os homens e ele serve a bebida com um único copo que vai passando de mão em mão.

Quando terminam o ciclo das novenas, a festa de Santos Reis culmina com a entrega da bandeira, a passagem das coroas para os festeiros do próximo ano e a esperada janta. A comida, que foi cuidadosamente elaborada durante dois dias pelas mulheres, nesse momento é servida exclusivamente pelos homens para todos os participantes da festa. Destaca-se também, de forma análoga à Romaria do Divino Pai Eterno, a importância da comida que se torna um elemento aglutinador que põe em destaque o universo doméstico e da cozinha. ${ }^{14}$

\section{Paródias: peões exaltados e desejados}

No povoado de Mirandópolis, há também a Festa de Nossa Senhora das Graças, em julho, que nos últimos dez anos também recebeu o nome de "Festa do Peão". Da mesma maneira que a Festa de Agosto em Mossâmedes, os preparativos iniciam-se com novenas e leilões. Na abertura, realiza-se uma procissão seguida de missa e o último leilão, que prenuncia o acontecimento mais esperado: o rodeio, seguido de baile madrugada adentro. $\mathrm{O}$ rodeio é um jogo realizado numa pequena arena, construída de forma improvisada para a festa, com cercas e bancos de madeira. Os competidores são rapazes do próprio município e de regiões vizinhas.

\footnotetext{
${ }^{14}$ No dia da entrega da bandeira, quando os foliões entram no galpão da festa, todos os festeiros homens rodeiam o grupo segurando panos brancos e vão os acompanhando até a chegada ao altar. Assim, é passado, então, o galho para o próximo que irá soltar a folia (que deverá organizar a sua saída $e$ organizar a janta) no ano que vem, e depois passada a coroa para o principal casal de festeiros.
} 
Nos rodeios, os peões, que têm uma posição subalterna no cotidiano em relação ao proprietário de terra e ao carreiro, são a atração principal. Esses eventos podem ocorrer dentro de uma festividade católica, como acontece na Festa de Nossa Senhora das Graças, em Mirandópolis, ou durante as grandes Exposições Agropecuárias, chamadas de Pecuárias, que acontecem nas cidades de Sanclerlândia e Goiás. Por contraste às Festas de Santos Reis, as Pecuárias são eventos que celebram o desenvolvimento urbano e aqueles que contribuem para esse processo modernizador, a elite local. ${ }^{15}$ Durante uma semana, o evento oferece exposições de gado de raça, torneios leiteiros, barracas de comida e bebida, rodeios, shows de música sertaneja e country.

Diferentemente do método frequentemente usado nas pequenas propriedades da região, no qual a ordenha é realizada manualmente pelos homens, nos torneios há modernas técnicas de ordenha mecanizada e belas vacas da raça Nelore nascidas de inseminação artificial. No período da festa, as manicures $e$ cabeleireiras da cidade não param de trabalhar e as lojas de roupa enchem-se de compradoras à procura de roupa nova pra festa. Muitos rapazes imitam as vestimentas dos peões de rodeio, à moda country. Moças também procuram usar calças justas, botas, chapéus de couro, cabelos soltos e bem penteados. À noite, período de maior concentração da festa, raramente as mulheres circulam sozinhas e estão sempre acompanhadas pelos seus companheiros ou por outras mulheres. Uma das maiores atividades noturnas é a paquera, o que significa que, "na festa, sem marido não presta", pois andar ou estar sozinho sugere estar disponível para novos encontros e namoros e ainda ser alvo de comentários entre pessoas conhecidas. Nos rodeios, os peões mostram seus dons de valentia em cima de boi e cavalo "brabo", exibindo cenas de coragem e habilidades para domar esses animais.

${ }^{15}$ Em Sanclerlândia, a exposição agropecuária já está em sua $20^{a}$ edição. 
As pecuárias e rodeios podem ser pensados como espaços reveladores de uma performance de gênero nos termos propostos por Judith Butler (2003). Para a autora, a performance de gênero busca desestabilizar a relação entre sexo e gênero por meio da paródia, uma imitação subversiva de uma cópia sem original.

Como em outros dramas sociais rituais, a ação do gênero requer uma performance repetida. Essa repetição é a um só tempo reencenação e nova experiência de um conjunto de significados já estabelecidos socialmente; e também é a forma mundana e ritualizada de sua legitimação (id.ib.:200).

Nesse sentido, os atributos de gênero não são expressivos, mas performativos e não podem instituir atos verdadeiros ou falsos, reais ou distorcidos, originais ou derivados.

No cenário goiano descrito, os peões de rodeio replicam, reinventam e exageram a imagem de um peão primordial, que estaria próximo do vaqueiro descrito por Euclides da Cunha, em Os Sertões, no início do século XX. A imagem do peão como um homem comum, que no cotidiano apresenta uma posição subalterna em relação ao patrão, é transfigurada para um espetáculo cênico que exibe, no espaço do rodeio, atos de valentia que representam um dos principais atributos da masculinidade. No rodeio, encena-se a domesticação de bois $e$ cavalos que se reproduz no cotidiano. Contudo, na vida diária, os peões domesticam animais que não são seus e, apesar de manterem uma relação praticamente pessoal com eles, como se fossem humanos, não são seus donos. Se a drag brinca com a distinção entre a anatomia do performista e o gênero que está sendo performado, o peão de boiadeiro, com a mesma anatomia do performista, joga com diferentes posições hierárquicas $e$ apresenta uma performance de gênero que é uma reinvenção $e$ um exagero do "original". 


\title{
Coda
}

\section{As três coisas que o peão mais gosta: Cerveja gelada, boi gordo na invernada e mulher pelada. \\ As três coisas que o peão menos gosta: Cerveja quente, boi doente e mulher da gente.}

(Verso declamado durante os rodeios)

Para Judith Butler (2003), a heterossexualidade compulsória regula o gênero como uma relação binária.

\begin{abstract}
A hipótese de um sistema binário dos gêneros encerra implicitamente a crença numa relação mimética entre gênero e sexo, na qual o gênero reflete o sexo ou é por ele restrito. Quando o status construído do gênero é teorizado como radicalmente independente do sexo, o próprio gênero se torna um artifício flutuante, com a consequência de que homem e masculino podem, com igual facilidade, significar tanto um corpo feminino como um masculino, $e$ mulher e feminino, tanto um corpo masculino como feminino (Butler, 2003:25).
\end{abstract}

No entanto, o próprio modelo heterossexual descrito no cenário goiano de festas rurais possui uma relação lógica com o modelo homossexual, ou melhor, com relações que privilegiam o modo "mesmo sexo". Assim, "gênero", nesse caso, pode ser compreendido como uma relação que diferencia pessoas de sexo cruzado e aproxima aquelas do mesmo sexo. É uma relação na qual tende a prevalecer a forma "mesmo sexo" nos encontros coletivos e concretiza-se na organização das redes de sociabilidade. Esse modelo está presente tanto nos períodos de festa quanto de trabalho. No entanto, durante as festividades, criam-se superposições, justaposições e replicações de atributos ligados a cada um dos sexos. Constroem-se representações hipermasculinas e hiperfemininas como o carreiro, o peão, o bicho 
custoso, o homem mole, a mulher trabalhadeira, a mulher semvergonha, a mulher à toa, etc.

Para Butler, a ideia da performance de gênero propõe uma relação crítica com as normas sociais e permite desfazer o estatuto essencialista da identidade de gênero. Esse processo necessita de um reconhecimento coletivo no qual se abre espaço para condições de vida mais inclusivas que questionem o dimorfismo sexual e a heterossexualidade compulsória. Desse modo, são os intersexos, os transexuais, as travestis, os gays e as lésbicas que buscam alternativas para transitar entre normas repressivas $e$ identidades coisificadas. Butler sugere, assim, uma concepção de humanidade que torne possível reconstruções corporais e amplie o leque de normas de reconhecimento para desejos, escolhas, identidades, corpos que escapem aos modelos hegemônicos. Dentro dessas reconstruções, seria possível imaginar corpos $e$ performances de gênero dissidentes dentro da matriz heterossexual? Ou a ampliação da concepção de humanidade e das construções coletivas de gênero deve implodi-la?

De um lado, não há apenas um único modelo de heterossexualidade e há outros fatores que interferem na sua imposição como forma hegemônica como relações familiares, diferenças geracionais, étnicas, de classe, de estilos de vida e de valores, diferenças territoriais, espaços urbanos ou rurais, etc. Dessa forma, deve haver brechas para que a heteronormatividade dialogue com modelos alternativos de sexualidade. De outro lado, a concepção de dimorfismo sexual não precisa estar colada à de heterossexualidade. O paradoxo dos intersexos e das travestis mostra-se significativo justamente por sugerir que, no primeiro caso, há corpos que, biologicamente, não respondem à uma lógica binária $e$, no segundo, há corpos que se recusam a se adequar ao modelo cultural imposto sem, no entanto, deixar de lado o desejo heterossexual.

No que diz respeito ao cenário da pesquisa, os eventos de pecuária, rodeio, folias assim como as festas de romaria, apresentam performances hiperbólicas de masculinidades $e$ 
feminilidades que propõem relações do tipo "mesmo sexo" descoladas da sexualidade. Ao mesmo tempo, essas performances, que se moldam a partir da lógica da segregação sexual e da homossociabilidade, reproduzem um modelo de heterossexualidade compulsória, mas que apresenta diferentes perspectivas sobre o universo rural.

Para além da divisão sexual do trabalho $e$ da complementaridade entre os sexos, as relações do tipo "mesmo sexo" põem em cheque a ideia de antagonismo entre homens $e$ mulheres dentro da matriz da heterossexualidade e, além disso, problematizam a reprodução mecânica da família patriarcal nas relações de gênero no campo. Nesse sentido, "a repetição 'imitativa' do original" (Butler, 2003) mostra a elaboração de uma imagem de gênero mimética que contém o seu próprio sexo. Apresentam-se hipermasculinidades e hiperfeminilidades replicadas e desejadas onde vale a pena dançar homem com homem, mulher com mulher.

\section{Referências bibliográficas}

ABRAmovay, M. e SiLVA, R., As relações de gênero na Confederação Nacional dos Trabalhadores Rurais (CONTAG). In: RoCHA, Maria Isabel Baltar. (org.) Trabalho e gênero: mudanças, permanências, desafios, Campinas, Unicamp/Nepo, 1998, pp.347-366.

ABRAmOVAY, M. e RUA, M.G. Companheiras de luta ou "coordenadoras de panelas"? As relações de gênero nos assentamentos rurais. Brasília, Unesco, 2000.

ALVES, M.F. P. Sexualidade e prevenção de DST/AIDS: representações sociais de homens rurais de um município da zona da mata pernambucana, Brasil. Cadernos de Saúde Pública, vol.19, supl. 2, Rio de Janeiro, 2003, pp.429-439. Disponível em www.scielo.br/pdf/csp/v19s2/a24v19s2.pdf

BitTencourt, L. Spinning Lives. Tese de doutorado em Antropologia, Cornell University, 1993. 
Homem com homem, mulher com mulher

BLAY, E. Trabalho feminino remunerado e não remunerado: uma falsa fonte de desigualdade. Cadernos CERU, nº 9, São Paulo, 1976.

BONI, V. Poder e igualdade: as relações de gênero entre sindicalistas rurais de Chapecó, Santa Catarina. Revista Estudos Feministas, vol.12, $\mathrm{n}^{\circ} \quad 1, \quad 2004$, pp.289-302. Disponível em www.scielo.br/pdf/ref/v12n1/21703.pdf

BRUMER, A. Previdência social rural e gênero. Sociologias $n^{\circ} 7$, ano 4, Porto Alegre, 2002, pp.50-81. Disponível em ww.scielo.br/pdf/soc/n7/a03n7.pdf

ButLeR, J. Problemas de gênero. Civilização Brasileira, Rio de Janeiro, 2003 [1990].

. Défaire le genre. Editions Amsterdam, Paris, 2006.

BUTO, A. e HORA, K. Mulheres e reforma agrária no Brasil. In: LOPES e ZARZAR. (orgs.) A experiência recente no Brasil. Brasília, MDA, 2008, pp.19-38.

CANDIDO, A. Os Parceiros do Rio Bonito. SP, Duas Cidades, 1987 [1964].

Coralina, C. Estórias da Casa Velha da Ponte. Global, SP, 1985.

CORDEIRO, R. e SCOTT, R.P. Mulheres em áreas rurais nas regiões Norte e Nordeste do Brasil. Revista Estudos Feministas, vol. 15, $\mathrm{n}^{\circ}$ 2, Florianópolis, 2007, pp.419-423. Disponível em http://www.scielo.br/pdf/ref/v15n2/a08v15n2.pdf

CORRÊA, M. Repensando a família patriarcal brasileira. In: CORRÊA, M. et alii. Colcha de retalhos - estudos sobre família no Brasil. Campinas, Ed. Unicamp, 1994, pp.5-16.

CunHA, E. da Os Sertões. Ed. Crítica, São Paulo, Brasiliense, 1985.

DEERE, C. D. Os direitos da mulher à terra e os movimentos sociais rurais na reforma agrária brasileira. Revista Estudos Feministas, vol.12, n ${ }^{\circ}$, 2004, pp.175-204.

DE GRANDI, A. B. Relações de Gênero em famílias agricultoras de Santa Catarina - Brasil. Cadernos de Pesquisa PPGSP/UFSC, $\mathrm{n}^{\circ} 21$, junho de 2000, pp.29-46.

ElIS, B. Os melhores contos. São Paulo, Global, 1994. 
FERREIRA, P. R. Os afectos mal-ditos: o indizível nas sociedades camponesas. São Paulo, Hucitec/ANPOCS, 2008.

FISCHER, I. e AlBUQUERQUE, L. O assalariamento da força de trabalho feminina rural. Cadernos CEAS (Centro de Estudos da Ação Social), $\mathrm{n}^{\circ}$ 162, Salvador-BA, 1995, pp.56-65.

Foucault, M. História da Sexualidade, vol. I - A vontade de saber. Rio de Janeiro, Graal, 1982.

FREYRE, Gilberto. Casa Grande \& Senzala. Rio de Janeiro, Editora Global, 1973. [1933]

FUKUI, L. Os papéis sexuais na organização familiar de sitiantes tradicionais no Brasil. Cadernos CERU, nº 8, USP, São Paulo, 1975.

GARCIA, L. et alii. A família como armadilha: a busca de fissuras no cotidiano de mulheres rurais nos Cariris paraibanos. João Pessoa, Ed. UFPB, 2011.

GOUVEIA, T. Muito trabalho e nenhum poder marcam as vidas das agricultoras familiares. Relatório. Observatório da Cidadania, Ibase, Rio de Janeiro, 2003, pp.44-49.

Grossi, M. Conventos e celibato feminino entre camponesas do Sul do Brasil. Horizontes Antropológicos, n¹, Porto Alegre-RS, 1995, pp.1-21. Disponível em http://www.miriamgrossi.cfh.prof.ufsc.br/pdf/conventos_celibato.pdf.

GuimarÃes RosA, J. Sagarana. Rrio de Janeiro, Nova Fronteira, 1984.

LISBOA, T. K. e LUSA, M. G. Desenvolvimento sustentável com perspectiva de gênero - Brasil, México e Cuba: mulheres protagonistas no meio rural. Revista Estudos Feministas, vol.18, n³, Florianópolis-SC, 2010, pp.871-887.

MACHADO, L. Perspectivas em confronto: relações de gênero ou patriarcado contemporâneo? Série Antropologia, UnB, Brasília, 2000.

MARTINEZ-Alier, V. As mulheres do caminhão de turma. Debate e Crítica (5), São Paulo, Fundação Carlos Chagas, mar. 1975.

MATHIEU, N. L'anatomie politique - catégorisations et idéologies du sexe. Paris, Coté Femmes, 1991. 
Homem com homem, mulher com mulher

MatTos, S. M. Artefatos de Gênero na Arte do Barro. Vitória-ES, EDUFES, 2001.

Melo, R. da M. S. e DuARTE, G. B. Impacto do Programa Bolsa Família sobre a frequência escolar: o caso da agricultura familiar no Nordeste do Brasil. Revista de Economia e Sociologia Rural, vol.48, n 3, 2010, pp.635-656.

MURARO, R. M. A sexualidade da mulher brasileira - corpo e classe social no Brasil. Petrópolis-RJ, Vozes, 1983.

NASCIMENTO, S. S. Faculdades Femininas e Saberes Rurais - uma etnografia sobre gênero e sociabilidade no interior de Goiás. Série Publicação Premiada, São Paulo, FFLCH/USP, 2008.

ORTNER, S. Está a mulher para o homem assim como a natureza para a cultura? In: ROSALDO, M. Z. e LAMPHERE, L. (coords.) A mulher, a cultura e a sociedade. Rio de Janeiro, Editora Paz e Terra, 1979, pp.93-120.

Paula ANDRADE, M. de. Conflitos agrários e memória de mulheres camponesas. Revista Estudos Feministas, vol.15, n 2, FlorianópolisSC, 2007, pp.445-451.

PAULILO, M. S. Movimento de mulheres agricultoras: terra e matrimônio. Cadernos de Pesquisa PPGSP/UFSC, n 21, junho de 2000, pp.01-15.

. A mulher e a terra no Brejo Paraibano. In: BRUSCHINI, M. C. e Rosemberg, F. (orgs.) Trabalhadoras do Brasil, São Paulo, Brasiliense, 1980.

Paulilo, M., De Grandi, A., Silva, M. M. Mulher e atividade leiteira: a dupla face da exclusão. Cadernos de Pesquisa PPGSP/UFSC, $\mathrm{n}^{\circ} 21$, junho de 2000.

PIRES, F., SANTOS, P. O. e SiLVA, J. Elas decidem? Analisando o papel familiar da mulher a partir do Programa Bolsa Família. CAOS Revista Eletrônica de Ciências Sociais. João Pessoa, UFPB, n ${ }^{\circ} 17$, 2011. Disponível em www.cchla.ufpb.br/caos/numero17.html

Portella, A. P. e Silva, C. F. Mulher e trabalho na agricultura familiar. Recife-PE, SOS Corpo, 2004.

QueIROZ, M. I. P. O Campesinato Brasileiro. Rio de Janeiro, Vozes, 1973. 
RODRIGUES, L. L. O avesso do casamento uma leitura antropológica do celibato entre camponeses ítalo e teuto-capixabas. Dissertação de Mestrado em Antropologia, Unb, Brasília, 1991.

SAFFiotti, H. e FerRAnTE, V. Famílias rurais no estado de São Paulo: algumas dimensões da vida feminina. In: BRUSCHINI, M. C. e ROSEMBERG, F. (orgs.) Trabalhadoras do Brasil, SP, Brasiliense, 1980.

SALES, C. de M. V. Mulheres rurais: tecendo novas relações $e$ reconhecendo direitos. Revista Estudos Feministas, vol.15, $\mathrm{n}^{\circ} 2$, Florianópolis-SC, 2007, pp.437-443.

SALVARO, G. I. J. Jornadas de trabalho de mulheres e homens em um assentamento do MST. Revista Estudos Feministas, vol.12, $\mathrm{n}^{\circ} 1$, Florianópolis-SC, 2004, pp.321-330.

SCOTT, R. P. Ruralidade e mulheres responsáveis por domicílios no Norte e no Nordeste. Revista Estudos Feministas, vol.15, $\mathrm{n}^{\circ} 2$, Florianópolis-SC, 2007, pp.425-436.

SILVA, M. A. de M.. Mulheres bóias-frias a caminho do eito. In: CostA, A. O. e BRUSCHINI, M. M. Entre a virtude e o pecado. Campinas-SP, Rosa dos Tempos/FCC, 1992.

SILVA, O. R. da. Status e papéis sócio-econômicos da mulher no bairro rural de Palmeirinhas, do sertão de Itapecerica. In: Cadernos CERU, $\mathrm{n}^{\circ} 1,1968$.

SIMMEL, G. Sociabilidade - um exemplo de sociologia pura ou forma. In: FiLHO, E. de M. (org.) George Simmel - Sociologia. São Paulo, Ática, 1983, pp.165-181.

StRATHERN, M. O gênero da dádiva. Problemas com as mulheres e problemas com a sociedade na Melanésia. Campinas-SP, Editora Unicamp, 2006.

STROPASOLAS, V. L. O valor (do) casamento na agricultura familiar. Revista de Estudos Feministas, vol.12, n 1 , Florianópolis-SC, 2004, pp.253-267.

VAN DER SCHAAF, A. Jeito de mulher rural: a busca de direitos sociais e da igualdade de gênero no Rio Grande do Sul. Sociologias, n ${ }^{\circ}$, Porto Alegre, 2003, pp. 412-442. 
Homem com homem, mulher com mulher

VINCENT, J. A sociedade agrária como fluxo organizado: processos de desenvolvimento passados e presentes. In: FELDMAN-BIANCO, B. (org.) A antropologia das sociedades contemporâneas - métodos. São Paulo, Global, 1987, pp.375-397.

WitTig, M. La Pensée Straight. Paris, Balland, 2001.

WoOrTMAnN, E. Herdeiros, parentes e compadres. São Paulo, Hucitec, 1995.

WOORTMANN, K. Com parente não se neguceia. Anuário Antropológico/87, Unb/ Tempo Brasileiro, 1990, pp.11-73. 